\title{
Iron deficiency anemia caused by nonspecific (idiopathic) small bowel ulceration: An uncommon presentation of an uncommon disease
}

\author{
Gabriele Capurso $M D^{1}$, Edith Lahner $M D^{1}$, Nadia Pallotta $M D^{2}$, \\ Francesco Panzuto $M D^{1}$, Gianfranco Delle Fave $M D^{1}$, Bruno Annibale $M D^{1}$
}

G Capurso, E Lahner, N Pallotta, F Panzuto, G Delle Fave, B Annibale. Iron deficiency anemia caused by nonspecific (idiopathic) small bowel ulceration: An uncommon presentation of an uncommon disease. Can J Gastroenterol 2002;16(12):855-859.

Ulcers of the small bowel are rare, and in most cases are due to infections, inflammatory bowel diseases, malignancies or drugs. When none of these causes is recognized, they are classified as 'nonspecific' or idiopathic. Such lesions are uncommon, and in most cases present with occlusion. A case of a middle-aged woman with iron deficiency anemia due to occult bleeding, with negative gastroscopy and colonoscopy is presented. The diagnosis of a small bowel pathology resembling Crohn's disease was made by small bowel follow through and small intestine contrast ultrasonography. An ileal ulcer was identified at surgery, and after resection the patient experienced a stable recovery from the anemia without ulcer recurrence. Neither histology nor clinical or biochemical features suggested the diagnosis of an inflammatory bowel disease. Other possible causes were unlikely and the lesion was therefore diagnosed as idiopathic. This report also focuses on the need and the modality to investigate the small bowel in iron deficiency anemia patients.
Anémie ferriprive causée par un ulcère aspécifique (idiopathique) de l'intestin grêle : manifestation rare d'une maladie rare

\begin{abstract}
RÉSUMÉ : Les ulcères de l'intestin grêle sont rares et, la plupart du temps, ils sont causés par des infections, des maladies inflammatoires de l'intestin, des tumeurs malignes ou des drogues. Lorsque aucun des ces facteurs étiologiques n'est mis en cause, on les qualifie d' « aspécifiques » ou d'idiopathiques. Ces lésions se rencontrent rarement et, en général, elles se manifestent par une occlusion. Voici le cas d'une femme d'âge moyen, qui présentait de l'anémie ferriprive secondaire à des saignements occultes mais chez qui la gastroscopie et la coloscopie étaient négatives. Un diagnostic de maladie de l'intestin grêle ressemblant à la maladie de Crohn a été posé à la suite d'un transit baryté et d'une échographie de contraste de l'intestin grêle. Un ulcère iléal a été repéré à la chirurgie et, après sa résection, la patiente s'est bien remise de l'anémie, sans réapparition de l'ulcère. Ni l'examen histologique, ni le tableau clinique, ni les examens biochimiques ne laissaient croire à une maladie inflammatoire de l'intestin. Les autres causes possibles ont été jugées improbables; la lésion a donc été classée comme idiopathique. L'article fait également ressortir la nécessité de l'exploration de l'intestin grêle et la pertinence du choix des examens chez les patients atteints d'anémie ferriprive.
\end{abstract}

Key Words: Iron deficiency anemia; Nonspecific ulcer; Small bowel; Ultrasonography

\footnotetext{
${ }^{1}$ Digestive and Liver Disease Unit II Medical School, Ospedale Sant'Andrea, Rome; ${ }^{2}$ Department of Clinical Science University La Sapienza, Rome, Italy

Correspondence and reprints: Dr Bruno Annibale, Department of Gastroenterology, II Clinica Medica, Policlinico Umberto I, Università La Sapienza, Roma, Viale del Policlinico 5, 00161, Roma, Italy. Telephone +39-06-4455292, fax +39-06-4455292, e-mail bruno.annibale@uniroma1.it
}

Received for publication July 5, 2002. Accepted October 7, 2002 
U lcers of the small intestine, distal to the duodenum, are rare (1). The most common causes of these uncommon lesions are infectious diseases, celiac disease, inflammatory bowel diseases, malignancies, systemic diseases or drugs. When none of these causes are clearly recognized, these lesions are described as nonspecific or idiopathic $(1,2)$. We report the unusual case of a middle-aged woman with refractory iron deficiency anemia (IDA) and no specific gastrointestinal complaints or manifest bleeding, caused by small bowel ulceration of unknown origin, and diagnosed by radiological and ultrasonographical techniques. After surgery a stable reversal of iron deficiency anemia without evidence of ulcer recurrence was observed.

\section{CASE PRESENTATION}

A 55-year-old woman was referred to the authors' gastroenterology department for evaluation of IDA (hemoglobin $5.25 \mathrm{mmol} / \mathrm{L}$, ferritin $5 \mu \mathrm{g} / \mathrm{L}$, mean cell volume $72 \mathrm{fL} / \mathrm{L}$ ) diagnosed one month before due to the sudden appearance of fatigue and dyspnea. A single fecal occult blood test was negative, and her primary care physician first referred her for a hematological consultation, which excluded the possibility of hematological diseases. Subsequently, in accordance with previously published study protocols $(3,4)$, the patient was referred to the authors' department for a gastrointestinal evaluation. The woman had a hysterectomy at 39 years of age and a laparoscopic cholecystectomy at 48 years of age; she was a blood donor, and showed no evidence of anemia six months before the diagnosis. She had no relevant diseases and no family history of gastrointestinal pathologies. The dietary iron intake was considered normal. When specifically asked, she denied gastrointestinal complaints other than an episodic mild abdominal pain, with no need of treatment or medical care. The patient also denied consumption of any drugs, including over the count- er medications, except for a single episode of influenza with backache treated with ketorolac at low doses for three days (about three months before the diagnosis of IDA). A complete colonoscopy and a gastroscopy with gastric and duodenal biopsies to rule out possible bleeding and nonbleeding-related gastrointestinal causes of IDA were carried out, as described elsewhere (3). All investigations showed negative results. According to published guidelines, initial small bowel investigations in patients with nontransfusion-dependant IDA, especially in the absence of evidence of bleeding and of specific gastrointestinal symptoms, is not suggested $(5,6)$. The patient was prescribed oral iron therapy, and a three month follow-up was scheduled. Despite iron therapy, three months later she still had IDA, as detailed in Table 1. Fecal occult blood was repeated on three consecutive samples, with positive results on two. The patient was still asymptomatic; specifically, she denied abdominal pain, manifest bleeding, weight loss, fever or diarrhea. The small bowel was then evaluated with a small bowel follow through (SBFT) (Figure 1) and a small intestine contrast ultrasonography (SICUS) (Figure 2) (7). Both examinations revealed different narrowed segments of the distal ileum proximal to the terminal ileum, accompanied by antimesenteric small bowel dilation. Moreover, SICUS revealed increased wall thickness for a length of $15 \mathrm{~cm}$ along the distal ileum (Figure 2). These findings raised the suspicion of Crohn's disease or of a neoplasia. An abdominal magnetic resonance confirmed the thickening of the ileal wall for a length of about $10 \mathrm{~cm}$, with the absence of lymph nodes, stenosis or other significant findings. A colonoscopy, with ileoscopy of the last $15 \mathrm{~cm}$ of the terminal ileum, was repeated and resulted negative, including normal histology of the colon and of the terminal ileum. Stool cultures for bacteria (including salmonella, shigella, yersinia, campylobacter) and parasites, serology for human

\section{TABLE 1}

Biochemical features before surgery and at the three and six month follow-up

\begin{tabular}{lccc}
\hline & Before surgery & $\begin{array}{c}\text { Three months } \\
\text { after surgery }\end{array}$ & $\begin{array}{c}\text { Six months } \\
\text { after surgery }\end{array}$ \\
\hline Hemoglobin (mmol/L) & $\mathbf{5 . 2 5}$ & 8.50 & 8.57 \\
Mean cell volume (fL/L) & 65 & 67 & 78 \\
Ferritin $(\mu \mathrm{g} / \mathrm{L})$ & $\mathbf{9}$ & 120 & 61 \\
EMA Immunoglobulin (IG) A & negative & - & - \\
EMA IgG & negative & - & - \\
AGA IgA & negative & - & - \\
C-reactive protein & negative & - & - \\
ESR (NV $\leq 10)$ & 10 & 6 & 8 \\
Serum proteins (NV 65-83 g/L) & 65.4 & 73.4 & 74 \\
Gammaglobulinemia (g/L) & 6.5 & 10 & 10 \\
IgG (NV 8-17 g/L) & $\mathbf{6 . 2 9}$ & 10.2 & - \\
IgM (NV 0.6-3.7 g/L) & 0.37 & 1.35 & - \\
IgA (NV 0.8-4.5 g/L) & 3.04 & 2.89 & - \\
Fecal occult blood & positive & negative & negative \\
\hline
\end{tabular}

Abnormal values are reported in bold. AGA Antigliadin antibodies; EMA Antiendomysium antibodies; ESR Erythrocyte sedimentation rate; NV Normal values 


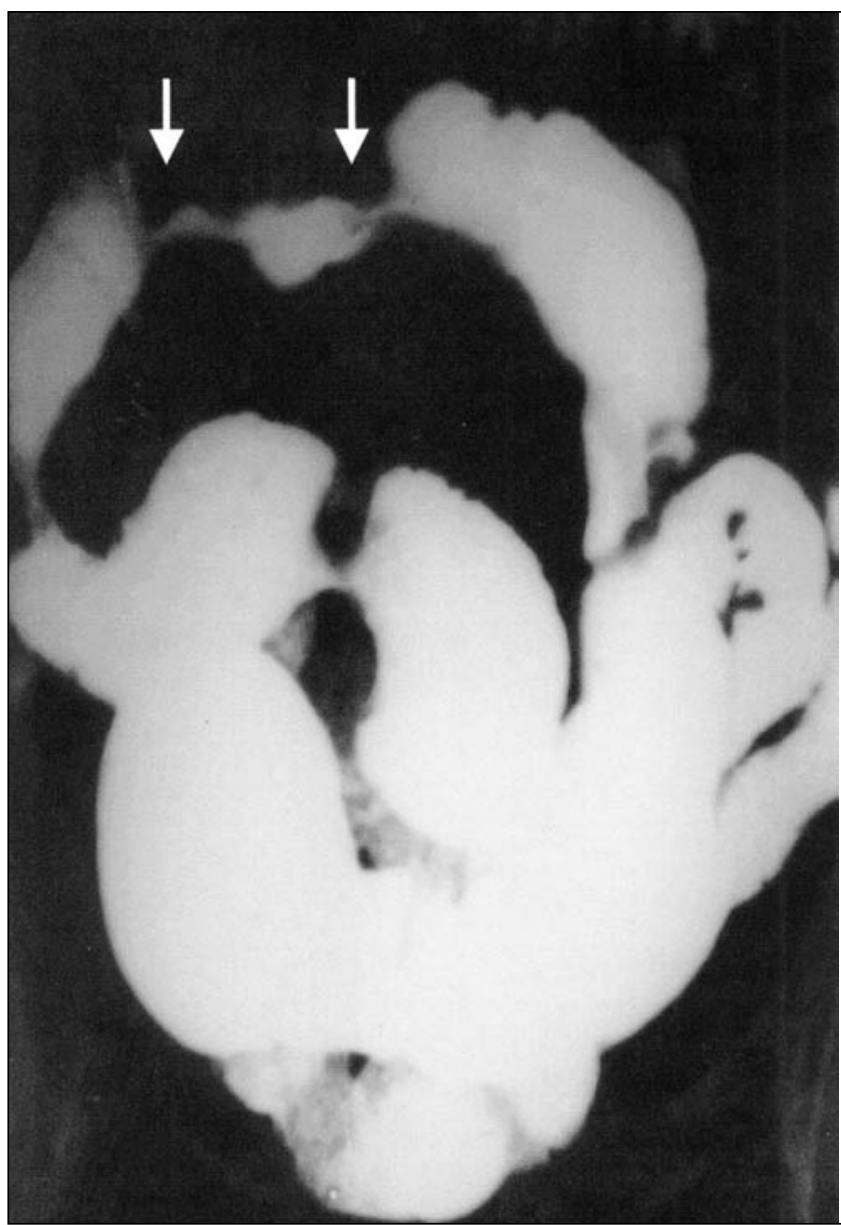

Figure 1) Small bowel follow through: a radiogram showing two segments of preterminal ileum with lumen narrowings (one indicated by arrows) and dilations

immunodeficiency virus (HIV) and cytomegalovirus (CMV) and a standard chest $\mathrm{x}$-ray were also negative. All other laboratory tests, including erythrocyte sedimentation rate, C-reactive protein, antiendomysium antibodies and fasting gastrin levels were in the normal range, the only pathological finding was a mild hypogammaglobulinemia with decreased immunoglobulin $\mathrm{G}$ and immunoglobulin $\mathrm{M}$ (Table 1). The patient was referred to the authors' surgery department with a suspected diagnosis of either Crohn's disease or of a lymphoma. An explorative laparotomy demon-

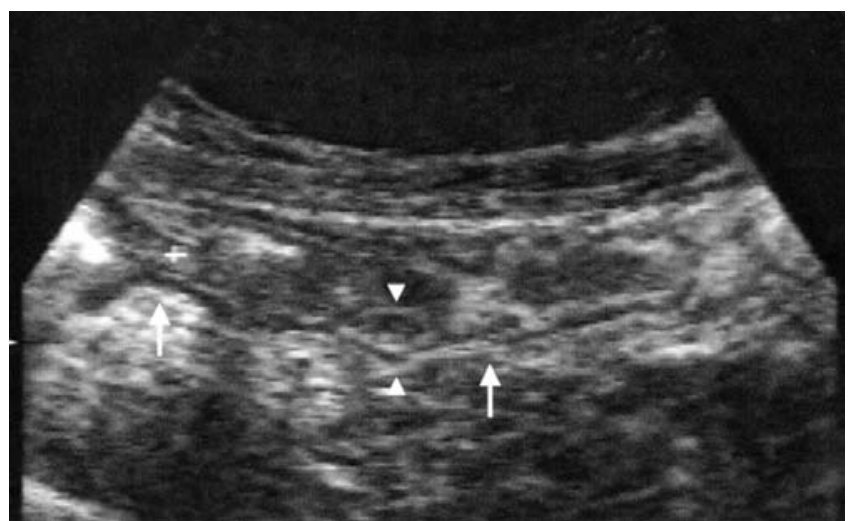

Figure 2) Small intestine contrast ultrasonography in longitudinal scan showing a reduced lumen diameter (arrows) and an increased wall thickness. All five layers of the intestinal wall are represented (arrow heads), beginning from the lumen: an echogenic layer, a thin hypoechogenic layer, a thicker echogenic layer, an additional hypoechogenic layer and the outer echogenic layer

strated a single ileal ulcer of $3 \times 2 \mathrm{~cm}$, located about $40 \mathrm{~cm}$ proximally to the ileocecal valve, and diffuse narrowing of the lumen along the distal ileum for a length of about 15 $\mathrm{cm}$. Intraoperative enteroscopy was negative all along the remaining small intestine. Sixteen centimetres of ileum were resected, and a termino-terminal anastomosis was made. Some mesentheric lymph nodes were also taken for histological examination. Histology of the ileal specimens demonstrated a nonspecific lymphomononucleate infiltration of the mucosa, with no granulomas or inclusion bodies. The picture was considered that of a nonspecific inflammatory process. Lymph nodes histology was negative. Three months after surgery the reversal of IDA, in absence of any iron therapy, as well as of the previously described hypogammaglobulinemia were observed. Similar results were reported six and 12 months after surgery. At the six month follow-up visit, a SICUS was also performed with demonstration of no luminal abnormalities.

\section{DISCUSSION}

We report the case of a middle-aged woman with IDA and no gastrointestinal complaints in whom after an extensive diagnostic workout, a small bowel nonspecific ulcer was found to be the cause of the anemia that reversed after surgery.

\section{TABLE 2}

\section{Possible causes of small bowel ulcers}

Infections

Neoplasms

Inflammation

Drugs

Systemic diseases

Vascular diseases

Others

Nonspecific (idiopathic)
Tubercolosis, cytomegalovirus, syphilis, typhoid, yersinia, campylobacter, parasites, human immunodeficiency virus

Zollinger-Ellison syndrome, carcinoid, lymphoma, adenocarcinoma, melanoma

Crohn's disease, celiac disease, eosinophilic enteritis

Potassium chloride, nonsteroidal anti-inflammatory drugs, acetylsalicylic acid

Erythematosus, Behcet's syndrome, amyloidosis

Ischemia, vasculitis

Radiation, arsenic, uremia

Idiopathic chronic ulcerative enteritis, nonspecific small bowel ulcers 
The small bowel is an uncommon site of gastrointestinal bleeding, either overt or occult (8). Vascular lesions account for $70 \%$ to $80 \%$ of these cases (8). Small bowel ulcers are much less common causes of occult bleeding and consequent IDA. Most of them are caused by drugs, infections, and neoplasms or by inflammatory pathologies (Table 2) $(1,2)$. A small quota of lesions with no recognized cause is described as nonspecific or idiopathic (1). Two different syndromes of idiopathic small bowel ulcerations have been described: nonspecific ulcers and idiopathic chronic ulcerative enteritis (9). The second presents with malabsorption and diarrhea, is usually diffused to the entire small bowel, and in most cases is associated with celiac disease, lymphoma or hypogammaglobulinemia (10). On the contrary, small bowel nonspecific ulcers, like the one diagnosed in this patient, are usually solitary lesions and are not associated with other diseases or with malabsorption. Most of them are diagnosed because of small bowel obstruction, and about $70 \%$ of the ulcers are located in the distal ileum (11).

Up to the end of the 1960 s, about 400 cases of small bowel nonspecific ulcers had been described (12-14). Many of the cases described in the 1960s and 1970s were due to potassium chloride tablets (11-14). Since the removal of these drugs from the market, the number of described cases has decreased (11), with fewer reports in the 1970s and 1980s (15-25), and, to our knowledge, none in the 1990s. The possible etiology of these lesions remains unclear. Glynn et al (20) described two cases of small bowel ulcers associated with cardiovascular disease with bad prognosis, and raised the hypothesis that ischemic damages could be the cause of such lesions. The Mayo Clinic reported that approximately $19 \%$ of patients had concomitant cardiovascular disease but an ischemic cause was considered unlikely (11). The possibility of an undiagnosed infectious etiology should also be considered, even in the absence of suggestive symptoms. In the past few years, some cases of nonspecific ileal ulcers caused by CMV infection (26), even in immunocompetent subjects (27), and by HIV have been described (28). In the present case the most common infectious causes, including CMV and HIV, had been excluded. After the SBFT and SICUS findings, we suspected Crohn's disease, even though no clinical or biochemical features of an inflammatory bowel disease were reported. Histology excluded malignancies and was not diagnostic for an inflammatory bowel disease. Unfortunately antiSaccharomyces cerevisiae antibodies were not evaluated. However, although Crohn's disease has rarely been reported to present with IDA (29), it seems to be unlikely in this patient. Only a longer follow-up will definitively exclude this diagnosis.

The association between celiac disease and idiopathic ileal ulcerations has been well demonstrated (30), but in this patient there was no evidence of malabsorption or of villous atrophy, and anti-antiendomysium antibodies were also negative. The only possible clinical suspect for the cause of the ulcer was the consumption of ketorolac in the previous months, in low doses (10 mg daily) and for just three days. Moreover, while it is well known that a quota of patients chronically treated with nonsteroidal anti-inflammatory drugs develop small bowel ulcers (31), ketorolac has never been described among drugs responsible for small bowel lesions (1), and it is highly unlikely that a short term course at low doses is responsible for the observed findings (32). Therefore, the diagnosis of nonspecific small bowel ulcer was made.

Surgery led to reversal of IDA, with normal clinical, biochemical and imaging findings during the follow-up, and no signs of ulcer recurrence at SICUS. We also observed a reversal of the previous mild hypogammaglobulinemia, a finding that has been reported to be associated with idiopathic chronic ulcerative enteritis (the more severe form of idiopathic small bowel ulcerations [10]) but never, until now, with small bowel nonspecific ulcers. The reason for the observed transient hypogammaglobulinemia is uncertain, but this finding did not seem to be part of a protein losing enteropathy.

Apart from the possible causes of the observed lesion, this report also underlines the importance of the diagnostic approach to the small bowel in IDA patients. The need and the modalities for evaluation of the small bowel in patients with IDA and negative endoscopic investigations is debatable, and recent guidelines do not suggest routine small bowel investigations in patients with IDA $(5,6)$. The diagnostic yield of small bowel radiology in patients with IDA is low, ranging from $0 \%(33,34)$ to $6.5 \%(35)$. Enteroscopy diagnoses a larger percentage of patients with overt bleeding (36). However, the diagnostic yield of push enteroscopy in patients with IDA and no signs of bleeding, as our patient was, is much lower (37). In our report the diagnosis of small bowel pathology was made by SBFT and SICUS, a widely available, inexpensive and nondemanding ultrasonography technique that has been demonstrated to have the same accuracy of SBFT (7). The observed nonspecific lesion, as the majority of those previously described (11), was localized in the distal ileum, well beyond the possible reach of a push enteroscope. Moreover, the Mayo Clinic reported that approxiamately $13 \%$ of cases presented with IDA (11), and some other cases of patients with IDA as only presenting symptom have been reported $(22,23)$. Therefore, even if IDA is not a common presentation of nonspecific small bowel ulcers, most of these lesions would probably be undiagnosed unless a small bowel imaging technique is used in IDA patients.

\section{CONCLUSIONS}

It is plausible that in the near future wireless video-capsule endoscopy (38) will become the first line procedure for the evaluation of the small bowel in patients with IDA and negative gastroscopy and colonoscopy. It has recently been reported that capsule endoscopy is able to identify small bowel lesions beyond the reach of push enteroscopy, including ileal ulcers. Capsule endoscopy is safe, and this method is preferred by patients (39). It is therefore tempting to hypothesize that idiopathic small bowel lesions as that described in 
our report will be diagnosed more frequently than expected in patients with either occult bleeding or IDA.

ACKNOWLEDGEMENTS: This work was supported by the interuniversity cofinanced program 9906218982 (1999) from the Italian Ministry for University and Scientific and Technological Research (MURST), by a grant from Ministero Sanità (Ricerca Finalizzata, 229/99) Rome, Italy, and Fondazione Italiana per le Malattie Digestive (FIMAD)

\section{REFERENCES}

1. Rai R, Bayless TM. Isolated and diffuse ulcers of the small intestine. In: Sleisenger MH, Fordtran JS, eds. Gastrointestinal Disease, 6th edn. Philadelphia: WB Saunders, 1998:1771-8.

2. Guest JL Jr. Nonspecific ulceration of the intestine. Int Abstr Surg 1963;117:409-16.

3. Annibale B, Capurso G, Chistolini A, et al. Gastrointestinal causes of refractory iron deficiency anemia in patients without gastrointestinal symptoms. Am J Med 2001;111:439-45.

4. Marignani M, Delle Fave G, Mecarocci S, et al. High prevalence of atrophic body gastritis in patients with unexplained microcytic and macrocytic anemia: A prospective screening study. Am J Gastroenterol 1999;94:766-72.

5. American Gastroenterological Association medical position statement: Evaluation and management of occult and obscure gastrointestinal bleeding. Gastroenterology 2000;118:197-200.

6. Goddard AF, McIntyre AS, Scott BB. Guidelines for the management of iron deficiency anemia. Gut 2000;46(Suppl IV):IV1-5

7. Pallotta N, Baccini F, Corazziari E. Small intestine ultrasonography (SICUS) in the diagnosis of small intestine lesions. Ultrasound Med Biol 2001;27:335-41.

8. Lewis BS. Small intestinal bleeding. Gastroenterol Clin North Am 2000;29:67-95.

9. Karnam US, Rosen CM, Raskin JB. Small bowel ulcers. Curr Treat Options Gastroenterol 2001;4:15-21.

10. Ruan EA, Komorowski RA, Hogan WJ, Soergel KH.

Nongranulomatous chronic idiopathic enterocolitis: Clinicopathologic profile and response to corticosteroids. Gastroenterology 1996;111:629-37.

11. Boydstun JS Jr, Gaffey TA, Bartholomew LG. Clinicopathologic study of nonspecific ulcers of the small intestine. Dig Dis Sci 1981;26:911-6.

12. Watson MR. Primary nonspecific ulceration of the small bowel. Arch Surg 1963;87:600-3.

13. Wilson IH, Cooley NV, Luibel FJ. Nonspecific stenosing small bowel ulcers: Experience in one California county. Am J Gastroenterol 1968;50:449-55.

14. Davies DR, Brightmore T. Idiopathic and drug-induced ulceration of the small intestine. Br J Surg 1970;57:134-9.

15. Graham DY, Bynum TE. Primary nonspecific small bowel ulceration as a source of chronic bleeding. Report of a case and review of the approach to localization of the site of small bowel hemorrhage. Am J Gastroenterol 1974;62:350-5.

16. Ihse I, Lunderquist A, Akerman M. Chronic bleeding from a primary non-specific small intestinal ulceration localized by angiography. Acta Chir Scand 1978;144:189-92.

17. Strodel WE, Eckhauser FE, Simmons JL. Primary ulceration of the ileum. Dis Colon Rectum 1981;24:183-6.
18. Reid J, Gilmour HM, Holt S. Primary non-specific ulcer of the small intestine. J R Coll Surg Edinb 1982;27:228-32.

19. Borsch G, Jahnke A, Bergbauer M, Nebel W. Solitary nonspecific ileal ulcer. Diagnosis by coloileoscopy in a patient with previously assumed irritable bowel syndrome. Dis Colon Rectum 1983;26:734-7.

20. Glynn MJ, Pendower J, Shousha S, Parkins RA. Recurrent bleedingfrom idiopathic ulceration of small bowel. Br Med J (Clin Res Ed) 1984;288:975-6.

21. Thomas WE, Williamson R. Idiopathic ulceration of the small bowel. Br Med J (Clin Res Ed) 1984;288:1835.

22. Thomas WEG, Williamson RCN. Nonspecific small bowel ulceration. Postgrad Med J 1985;61:587-91.

23. Ballantyne KC, Morris DL, Hawkey CJ, Hardcastle JD. Haemorrhage from idiopathic annular ulcers of the small intestine. Ann R Coll Surg Engl 1986;68:168-9.

24. Harling $\mathrm{H}$, Laustsen J. Primary non-specific ulcer of the small bowel. Acta Chir Scand 1985;151:289-90.

25. Cavallaro V, Racalbuto A, Russello D, Succi L, Fragati G, Catania $\mathrm{V}$. Intestinal perforation caused by non specific idiopathic ulcer of the small intestine. A case report. Ital J Surg Sci 1989;19:395-8.

26. Weber FH Jr, Frierson HF Jr, Myers BM. Cytomegalovirus as a cause of isolated severe ileal bleeding. J Clin Gastroenterol 1992;14:52-5.

27. Taniwaki S, Kataoka M, Tanaka H, Mizuno Y, Hirose M. Multiple ulcers of the ileum due to cytomegalovirus infection in a patients who showed no evidence of an immunocompromised state. J Gastroenterol 1997;32:548-52.

28. Pouderoux P, Barbuat C, Said OH, Balmes JL. Chronic idiopathic ulcer of the ileum in the acquired immune deficiency syndrome. Am J Gastroenterol 1995;90:1890-1.

29. Raju GS, Bardhan KD, Taylor PC, Harvey L, Rigby CC. Manasew S. Atypical presentation of Crohn's disease: Severe, recurrent iron deficiency anemia dependent on blood transfusions. Am J Gastroenterol 1994;89:113-5.

30. Robertson DAF, Dixon MF, Scott BB, Simpson FG, Losowsky MS. Small intestinal ulceration: diagnostic difficulties in relation to coeliac disease. Gut 1983;24:565-74.

31. Bjorkman D. Nonsteroidal anti-inflammatory drug-associated toxicity of the liver, lower gastrointestinal tract, and esophagus. Am J Med 1998;105 (5A):17S-21S.

32. Reinhart DI. Minimising the adverse effects of ketorolac. Drug Saf 2000;22:487-97.

33. Rockey DC, Cello JP. Evaluation of the gastrointestinal tract in patients with iron-deficiency anemia. N Engl J Med 1993;329:1691-5.

34. Kepczyk MT, SC Kadakia. Prospective evaluation of gastrointestinal tract in patients with iron-deficiency anemia. Dig Dis Sci 1995;40:1283-9.

35. Gordon SR, Smith RE, Power GC. The role of endoscopy in the evaluation of iron deficiency anemia in patients over the age of 50 . Am J Gastroenterol 1994;89:1963-7.

36. Chak A, Cooper GS, Canto MI, Pollack BJ, Sivak MV Jr. Enteroscopy for the initial evaluation of iron deficiency. Gastrointest Endosc 1998;47:144-8.

37. Landi B, Tkoub M, Gaudric M, et al. Diagnostic yield of push-type enteroscopy in relation to indication. Gut 1998;42:421-5.

38. Appleyard M, Glukhovsky A, Swain P. Wireless-capsule diagnostic endoscopy for recurrent small-bowel bleeding. N Engl J Med 2001;344:232-3.

39. Lewis BS, Swain P. Capsule endoscopy in the evaluation of patients with suspected small intestinal bleeding: results of a pilot study. Gastrointest Endosc 2002;56:349-53. 


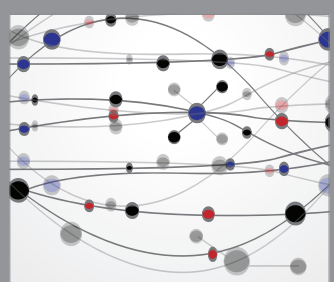

The Scientific World Journal
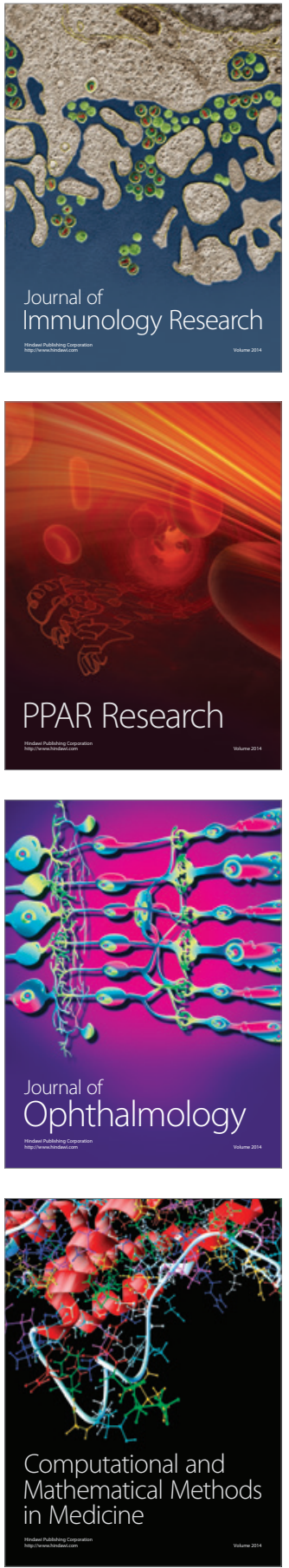

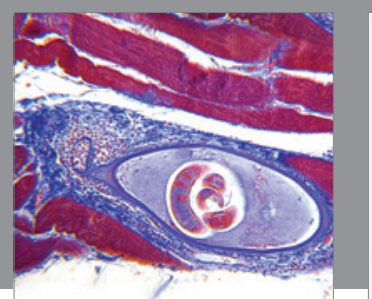

Gastroenterology Research and Practice

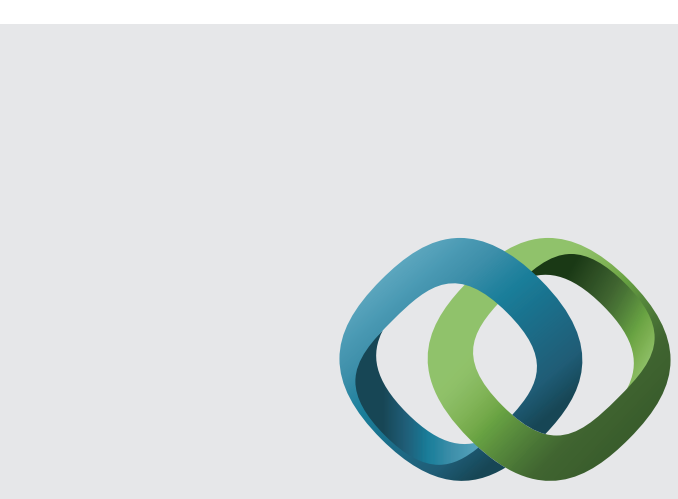

\section{Hindawi}

Submit your manuscripts at

http://www.hindawi.com
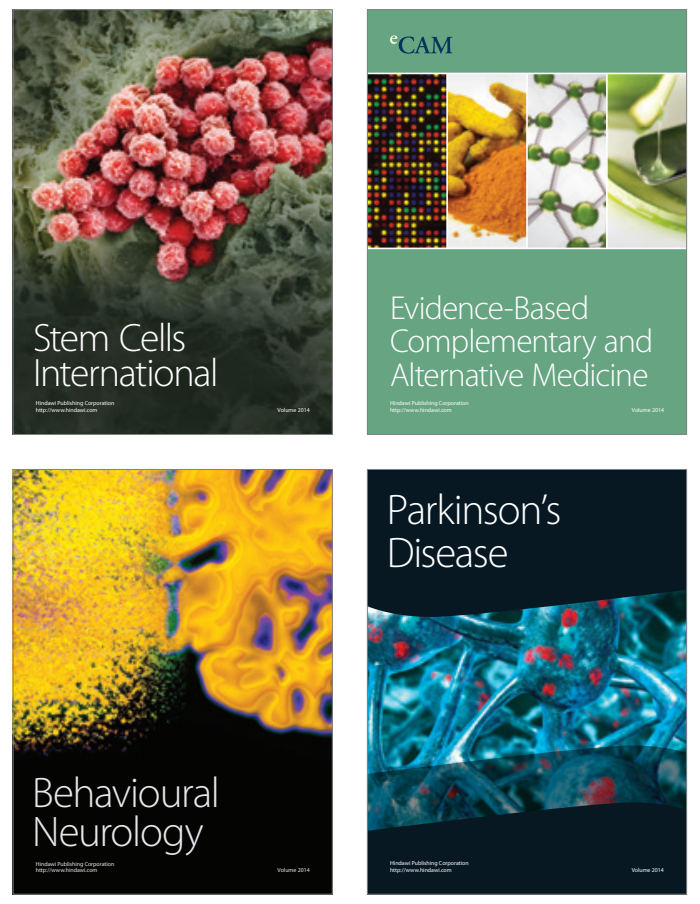
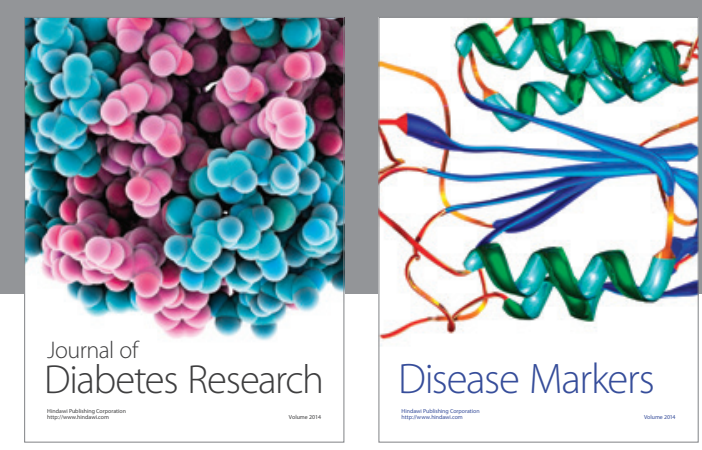

Disease Markers
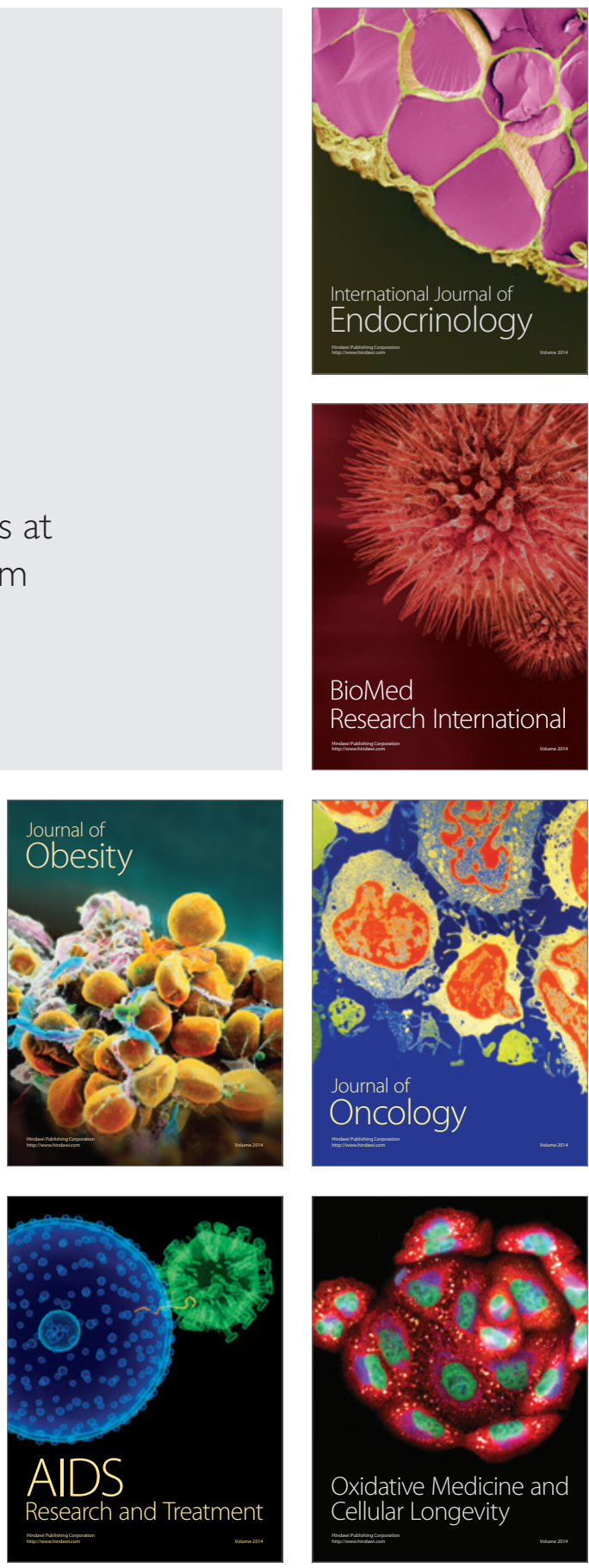